Artigo / Article

\title{
Triagem de hemoglobinopatias e avaliação da degeneração oxidativa da hemoglobina em trabalhadores portadores do traço falciforme (HbAS), expostos a riscos ocupacionais
}

\author{
Screening of abnormal hemoglobin and the evaluation of oxidative degeneration of hemoglobin \\ among workers with the sickle cell trait (HbAS), exposed to occupational hazards
}

Isaac L. Silva Filho ${ }^{1,5}$

Marilda S. Gonçalves ${ }^{2,3}$

Elisângela V. Adôrno ${ }^{2,3}$

Dayse P. Campos ${ }^{1}$

Marcos K. Fleury ${ }^{4}$

\begin{abstract}
Desde os anos 40, quando foram realizados os primeiros trabalhos de triagem para hemoglobinas anormais na população brasileira, tem sido descrita uma elevada prevalência destas em nosso meio, especialmente a hemoglobina $S$ que, a despeito da heterogeneidade de sua distribuição geográfica, quase sempre é a mais freqüente nas diversas regiões estudadas. Aliado a este fato, estudos recentes têm demonstrado uma maior susceptibilidade desta a oxidação, tornando-a mais sensivel ao estresse oxidativo que a hemoglobina normal (HbAA), mesmo em se tratando de portadores heterozigotos $(H b A S)$. Tendo em vista que algumas substâncias químicas são comprovadamente meta-hemoglobinizantes, que alguns fatores ambientais podem influenciar na morbidade da anemia falciforme e também o pouco e controverso conhecimento de que se dispõe a respeito de portadores do traço falciforme, este estudo, além da pesquisa de hemoglobinas anormais, avaliou também a degeneração oxidativa da hemoglobina, através da pesquisa de corpos de Heinz e dosagem de meta-hemoglobina em uma população de trabalhadores portadores do traço falciforme, expostos a riscos ocupacionais. Foram triadas 2.190 amostras sangüineas entre Outubro de 1999 e Dezembro de 2001. A população estudada foi constituida de trabalhadores de ambos os sexos com idades variando entre 18 e 76 anos. Os resultados evidenciaram 4,7\% portadores de hemoglobinas anormais na população analisada, sendo que a hemoglobina $S$ foi a mais freqüente $-3,2 \%$ (71). Trabalhadores portadores do traço falciforme apresentaram uma chance 14 vezes maior de possuirem valores aumentados de meta-hemoglobina em relação aos trabalhadores com genótipo AA, porém, esta diferença não foi estatisticamente significativa. Rev. bras. hematol. hemoter. 2005;27(3):183-187.
\end{abstract}

Palavras-chave: Hemoglobinopatias; risco ocupacional; meta-hemoglobina; traço falciforme.

\footnotetext{
${ }^{1}$ Instituto de Pesquisa Clínica Evandro Chagas - Fundação Oswaldo Cruz - Rio de Janeiro-RJ.

${ }^{2}$ Centro de Pesquisa Gonçalo Muniz - Fundação Oswaldo Cruz - Salvador-BA.

${ }^{3}$ Universidade Federal da Bahia.

${ }^{4}$ Universidade Federal do Rio de Janeiro.

${ }^{5}$ Laboratório Central - Hospital Universitário - Universidade Federal de Juiz de Fora. do Trabalhador (NUST) - Fundação Oswaldo Cruz do Rio de Janeiro-RJ.

Correspondência para: Isaac Lima da Silva Filho

Instituto de Pesquisa Clínica Evandro Chagas (IPEC) - Fundação Oswaldo Cruz - Rio de Janeiro-RJ

Av. Brasil, 4365 - Manguinhos

21045-900 - Rio de Janeiro-RJ

Tel. (21) 3865-9543 / 3865-9622 - Fax: 2590-9988

E-mail:Isaac@ipec.fiocruz.br
}

Trabalho realizado no Serviço de Patologia Clínica do Instituto de Pesquisa Clínica Evandro Chagas (IPEC) e no Núcleo de Saúde 


\section{Introdução}

Depois de mais de 50 mil anos após o homem moderno ter migrado da África e ocupado sucessivamente todos os continentes da terra, dando origem à raça humana, eles voltariam a se encontrar novamente e o local combinado foi o Brasil. Índios, oriundos dos ameríndios, que vieram da Ásia e povoaram a América, portugueses e outros que vieram da Europa e negros escravos vindos do continente africano deram origem a um povo singular sob o ponto de vista genético, mistura esta inusitada, talvez jamais vista em toda a História. ${ }^{1}$

A herança do intenso processo de miscigenação sofrido no Brasil se refletiu nos aspectos culturais, sociais e genéticos. Dentre os muitos sinais herdados, estão alterações gênicas que podem resultar em doenças, como é caso das hemoglobinopatias. As anormalidades que resultam na alteração da molécula de hemoglobina estão entre as mais comuns e acometem milhões de pessoas em todo o mundo. As talassemias, herdadas dos europeus, asiáticos, entre outros, e a anemia falciforme, vinda com os escravos da África, estão entre as doenças genéticas mais comuns no mundo. Estimase que $10 \%$ da população mundial seja portadora dos genes da hemoglobina $\mathrm{S}$ e talassemias. ${ }^{2}$

No Brasil, as hemoglobinopatias hereditárias são doenças freqüentes na nossa população, constituindo um problema de saúde pública em nosso meio, ${ }^{3}$ demonstrando, portanto, a necessidade de incentivar medidas visando o rastreamento e orientação aos seus portadores.

A anemia falciforme é uma das doenças mais estudadas no mundo e, a cada ano, as descobertas sobre esta condição têm se refletido na melhoria da qualidade e aumento da expectativa de vida dos doentes. Porém, bem menos se sabe sobre o traço falciforme. É consenso tratar-se de uma condição benigna apresentando poucas ou nenhuma manifestação clínica ou laboratorial. Contudo, a sua morbidade depende de fatores ambientais, sendo relatado, na literatura, desde pequenos danos à saúde até manifestações clínicas graves, inclusive a morte destes indivíduos. ${ }^{4-8}$

Aliado a isso, estudos recentes têm reiterado uma maior susceptibilidade da hemoglobina $\mathrm{S}$ à oxidação, não importando seu genótipo ou sua concentração, quando comparado com a hemoglobina A. A simples presença desta é suficiente para causar a meta-hemoglobinização da hemoglobina. ${ }^{9}$

Algumas substâncias químicas, especialmente alguns derivados da anilina e do nitrobenzeno, são comprovadamente meta-hemoglobinizantes. Trabalhadores expostos ocupacionalmente a estas substâncias são obrigados por lei, segundo as normas regulamentadoras da saúde ocupacional no Brasil, a serem monitorados através da dosagem da metahemoglobina, levando-se em conta que seu aumento pode produzir danos oxidativos à hemoglobina. ${ }^{10}$ Milhares de casos de doenças profissionais e acidentes de trabalho são notificados anualmente e constituem hoje, no Brasil, um dos mais graves problemas de saúde pública. ${ }^{11}$

A avaliação do estresse oxidativo da hemoglobina em trabalhadores com o traço falciforme e expostos a fatores de riscos ocupacionais foi motivada devido ao escasso conhecimento que se possui sobre o assunto e baseado na comprovada maior susceptibilidade da hemoglobina $\mathrm{S}$ à oxidação, fato que poderia aumentar ainda mais os riscos desta exposição, principalmente àqueles agentes comprovadamente meta-hemoglobinizantes aos trabalhadores sem hemoglobinopatias.

\section{Casuística e Métodos}

O presente trabalho é um estudo descritivo, visando a identificação de hemoglobinas anormais e os efeitos da exposição a alguns fatores de risco ocupacionais sobre a hemoglobina de indivíduos portadores do traço falciforme e trabalhadores da Fundação Oswaldo Cruz do Rio de Janeiro (Fiocruz-RJ). Os fatores de risco avaliados foram a exposição a substâncias químicas e a fatores de risco ambiental e que incluía frio e calor excessivos e radiação.

Este trabalho foi realizado no Instituto de Pesquisa Clínica Evandro Chagas (Ipec) e no Núcleo de Saúde do trabalhador (NUST), ambos pertencentes à Fiocruz-RJ, no período compreendido entre Outubro de 1999 e Dezembro de 2001. Neste intervalo de tempo foram coletadas 2.190 amostras de sangue de trabalhadores que se submeteram aos exames periódicos preventivos, dentro de um Programa de Controle Médico e Saúde Ocupacional (PCMSO), solicitado pelo NUST.

As amostras sangüíneas foram colhidas com EDTA, e a série vermelha foi determinada no contador da Coulter, modelo T-890. As hemoglobinas variantes foram triadas por eletroforese em meio alcalino e a confirmação feita em meio ácido. Para o diagnóstico das talassemias beta foram utilizadas as dosagens de $\mathrm{HbA} 2$ e fetal. Para a talassemia alfa foi empregada a técnica de PCR, que foi realizada no Laboratório de Patologia e Biologia Molecular (LPBM) do Centro de Pesquisa Gonçalo Muniz da Fiocruz-BA. A avaliação da oxidação degenerativa da hemoglobina foi determinada pela dosagem de meta-hemoglobina ${ }^{12}$ e pela pesquisa de corpos de Heinz. A origem da meta-hemoglobinemia foi avaliada realizando-se a curva da meta-hemoglobina.

A dosagem de meta-hemoglobina foi realizada em um grupo aleatório de trabalhadores, porém, apenas os que apresentaram hemoglobina AA e informações sobre a exposição aos fatores de risco ocupacionais foram utilizados no estudo. Todos os portadores do traço falciforme foram reconvocados e, mediante consentimento livre e esclarecido, também foram submetidos à dosagem de meta-hemoglobina e, do mesmo modo que os trabalhadores com hemoglobina AA, somente aqueles dos quais se obtiveram informações sobre a exposição foram aproveitados. Quando a meta-hemoglobina 
se encontrava acima dos limites de referência considerado para o teste, que era de até $4 \%$, realizava-se a pesquisa de corpos de Heinz e a curva de meta-hemoglobina.

\section{Análise estatística}

Para a comparação de médias foi utilizado o teste tStudent e para avaliar a existência de associação utilizou-se o teste $\chi^{2}$ ou o teste exato de Fisher, quando o teste do $\chi^{2}$ não podia ser empregado. Na estimativa da medida de associação utilizou-se o intervalo de confiança de 95\%.

\section{Resultados}

Triagem das hemoglobinas: Das 2.190 amostras triadas, $1.150(52,5 \%)$ eram do sexo feminino e $1.040(47,5 \%)$ do sexo masculino, com idade variando entre 18 e 76 anos e média de $37,9 \pm 10,1$. Foram identificados $2.086(95,3 \%)$ trabalhadores com hemoglobinas normais (Hb.AA) e $104(4,7 \%)$ portadores de hemoglobinas anômalas (Tabela 1). Dentre as hemoglobinas anormais encontradas, a hemoglobina $\mathrm{S}$ foi a mais freqüente, tendo sido identificada em $76(3,4 \%)$ trabalhadores; deste total, $71(3,2 \%)$ eram portadores do traço falciforme (Hb.AS), sendo que quatro $(0,2 \%)$ apresentaram interação com a talassemia alfa (Hb.AS/tal. $\alpha)$ e um $(0,05 \%)$ indivíduo possuía anemia falciforme (Hb.SS).

Tabela 1

Freqüência dos diferentes genótipos de hemoglobinas identificados nos trabalhadores da Fiocruz-RJ

\begin{tabular}{lrc}
\hline Genótipo & $N^{\circ}$ de indivíduos & $\%$ \\
\hline A/A & 2.086 & 95,3 \\
A/S & 71 & 3,2 \\
Tal $\alpha$ & 12 & 0,5 \\
A/C & 09 & 0,4 \\
Tal $\beta$ & 06 & 0,3 \\
AS/Tal $\alpha$ & 04 & 0,2 \\
A/D & 01 & 0,05 \\
S/S & 01 & 0,05 \\
\hline Total & 2.190 & 100,00
\end{tabular}

A talassemia alfa foi encontrada em 16(0,7\%) trabalhadores, quatro deles $(0,2 \%)$ apresentando interação com o traço falciforme.

Todas as deleções nos casos de talassemia alfa foram $\alpha 3,7$ II, sendo todos os testes negativos para a deleção $\alpha$ 4,2 II.

Dentre as variantes moleculares, a hemoglobina $\mathrm{C}$ (HbAC), foi a segunda mais freqüente, tendo sido encontrada em nove $(0,4 \%)$ indivíduos. A talassemia beta heterozigota foi identificada em seis $(0,3 \%)$ trabalhadores e apenas um trabalhador $(0,05 \%)$ era portador da $\mathrm{Hb} . \mathrm{AD}$.

Avaliação da degeneração oxidativa da hemoglobina: Na tabela 2 observa-se a distribuição dos trabalhadores que
Tabela 2

Distribuição dos trabalhadores AA e AS que realizaram dosagem de meta-hemoglobina e sua relação com os fatores de riscos ambientais

\begin{tabular}{lccc}
\hline Genótipo & \multicolumn{2}{c}{$\begin{array}{c}\text { Exposição a } \\
\text { riscos ambientais }\end{array}$} & Total \\
& Sim & Não & \\
\hline A A & 66 & 15 & 81 \\
AS & 26 & 12 & 38 \\
\hline Total & 92 & 27 & 119
\end{tabular}

Tabela 3

Distribuição dos trabalhadores AA e AS que realizaram dosagem de meta-hemoglobina e sua relação com a exposição a substâncias químicas

\begin{tabular}{|c|c|c|c|}
\hline \multirow[t]{2}{*}{ Genótipo } & \multicolumn{2}{|c|}{$\begin{array}{c}\text { Exposição a } \\
\text { substâncias químicas }\end{array}$} & \multirow[t]{2}{*}{ Total } \\
\hline & Sim & Não & \\
\hline AA & 35 & 46 & 81 \\
\hline AS & 33 & 12 & 45 \\
\hline Total & 68 & 58 & 126 \\
\hline
\end{tabular}

realizaram dosagem de meta-hemoglobina, sua relação com os fatores de riscos ambientais e seus genótipos.

Na tabela 3 observa-se a distribuição dos trabalhadores que realizaram dosagem de meta-hemoglobina, sua relação com a exposição a substâncias químicas e seus genótipos.

A média da meta-hemoglobina do grupo AS foi ligeiramente maior $(3,7 \pm 0,8)$ que a do grupo $\mathrm{AA}(3,6 \pm 0,3)$, porém, não foi possível observar diferença significativa entre estas nos dois grupos de trabalhadores $(\mathrm{p}>0,14)$. Quando a comparação levou em consideração a exposição aos fatores de riscos ocupacionais avaliados, também não se observou diferença significativa.

Em relação aos indivíduos que apresentaram metahemoglobinemia ( $>4 \%$ ), não foi possível observar diferenças significativas entre os expostos e os não expostos aos fatores de riscos ocupacionais. No entanto, trabalhadores com HbAS apresentaram uma chance 14 [IC95\% 2,7; 99,3] vezes maior de possuírem aumento de meta-hemoglobina do que trabalhadores com $\mathrm{HbAA}(\mathrm{p}<0,001)$. A relação dos genótipos dos trabalhadores com a meta-hemoglobinemia encontrada observa-se na tabela 4.

Trabalhadores com HbAS e expostos a substâncias químicas, apresentaram uma chance 7,6 [IC95\% 0,8; 179,9] vezes maior de possuírem aumento de meta-hemoglobina do que trabalhadores com $\mathrm{HbAA}(\mathrm{p}<0,001)$. Os valores observados encontram-se na tabela 5 .

Observou-se que, dos 13 trabalhadores que apresentaram meta-hemoglobinemia, 11 eram portadores do traço falciforme e apenas dois possuíam HbAA (Tabela 4). 
Tabela 4

Resultado de meta-hemoglobina entre os trabalhadores com genótipos AA e AS

\begin{tabular}{|c|c|c|c|}
\hline \multirow[t]{2}{*}{ Genótipo } & \multicolumn{2}{|c|}{ Metahemoglobina } & \multirow[t]{2}{*}{ Total } \\
\hline & $\leq 4 \%$ & $>4 \%$ & \\
\hline$A A$ & 93 & 2 & 95 \\
\hline AS & 36 & 11 & 47 \\
\hline Total & 129 & 13 & 142 \\
\hline
\end{tabular}

Tabela 5

Resultado de meta-hemoglobina entre os trabalhadores com genótipos AA e AS expostos a substâncias químicas

\begin{tabular}{|c|c|c|c|}
\hline Genótipo & \multicolumn{2}{|c|}{ Meta-hemoglobina } & Tota \\
\hline A A & 34 & 1 & 35 \\
\hline AS & 27 & 6 & 33 \\
\hline Total & 61 & 7 & 68 \\
\hline
\end{tabular}

Das 11 curvas de meta-hemoglobina realizadas, oito foram semelhantes com as de origem tóxica.

Não foram observadas hemácias positivas para corpos de Heinz em trabalhadores com meta-hemoglobinemia.

\section{Discussão}

O Rio de Janeiro, cidade que, em determinados momentos durante o período que perdurou o tráfico de escravos, chegou a absorver pelo menos metade dos negros que chegavam em terras brasileiras, ${ }^{13}$ tem, deste modo, demonstrado uma alta freqüência de hemoglobinas de origem africana, especialmente a $\mathrm{Hb} \mathrm{S}$, conseqüência da forte influência da miscigenação negra na formação de sua população.

Em relação ao gene alfa, este não tem sido sistematicamente estudado na nossa população, embora a talassemia alfa $\left(-\alpha^{3.7}\right)$ seja a alteração mais freqüente entre os negros no Brasil. ${ }^{14}$ No Rio de Janeiro, apenas uma investigação até o momento foi realizada. Lima (1997) ${ }^{15}$ estudou a interação da talassemia alfa com a hemoglobina $\mathrm{S}$, através da técnica de Southern blotting em 89 pacientes portadores de anemia falciforme, tendo sido investigadas algumas das deleções mais freqüentes na população mundial $\left[\alpha_{-}{ }^{3.7}, \alpha_{-}{ }^{4.2},-{ }^{\text {MED }}\right.$, -_-SEA] e a única observada foi a $-\alpha^{3.7} \mathrm{~Kb}$ II. O presente estudo foi o primeiro a utilizar a técnica de PCR para uma população do Rio de Janeiro e também somente encontrou a deleção $\alpha-{ }^{3.7}$, sendo todos os testes negativos para a deleção $\alpha-{ }_{-}^{4.2}$.

Estudos têm mostrado que a hemoglobina $\mathrm{S}$ tem uma tendência inerente à auto-oxidação, apresentando uma exagerada geração de radicais livres, especialmente espécies ativadas de oxigênio, durante incubação in vitro. ${ }^{16}$ Dados da literatura nacional têm confirmado esses achados. Souza $(2001)^{9}$ demonstrou, avaliando alguns produtos de degrada- ção da hemoglobina - dentre eles a meta-hemoglobina -, que a simples presença da hemoglobina $\mathrm{S}$, independente do seu genótipo e de sua concentração, é suficiente para produzir a sua meta-hemoglobinização. Os resultados acima corroboram o estudo, mas o tamanho reduzido da amostra talvez possa explicar que, mesmo sendo maior a média da metahemoglobina em trabalhadores portadores do traço falciforme, esta não foi estatisticamente significativa.

Os fatores de riscos ocupacionais não influenciaram na média da meta-hemoglobina, tendo esta sido provavelmente ocasionada pela presença da hemoglobina $\mathrm{S}$, tendo em vista também o fato de que possuir o genótipo AS, independentemente de sua exposição, apresentou o dobro de chances de ter meta-hemoglobinemia (Tabela 4) do que aqueles expostos a substâncias químicas (Tabela 5).

Os resultados discretamente elevados observados nos trabalhadores com meta-hemoglobinemia e a rápida remoção que é feita pelo baço sadio dos corpos de Heinz da circulação periférica podem explicar o fato de não terem sido observadas hemácias contendo essas inclusões nas lâminas dos servidores examinados.

Algumas das principais diferenças na estrutura do grupamento heme, que caracterizam estados diferentes de hemoglobina, são evidenciados pelo seu espectro de absorção, que, no caso da meta-hemoglobina, tem seu pico nos comprimentos de onda $500 \mathrm{~nm}$ e $630 \mathrm{~nm} .{ }^{12}$ A curva de metahemoglobina dos trabalhadores que apresentaram metahemoglobinemia, na grande maioria dos casos $(72,7 \%)$ foi característica de meta-hemoglobina normal ou meta-hemoglobina A, nos levando a crer que este aumento seria de origem tóxica, provavelmente produzida pela oxidação da hemoglobina S, levando-se em consideração que, com exceção de dois trabalhadores, todos os outros eram portadores do traço falciforme e metade destes apenas estava exposta a substâncias químicas.

Entre os dois únicos trabalhadores com hemoglobina normal que apresentaram meta-hemoglobinemia, somente no que estava exposto a substâncias químicas foi possível ser realizada a curva, tendo essa sido compatível com origem tóxica. Nesse caso, pode ser que esse fator de risco estivesse influenciando no aumento dessa.

\section{Conclusões}

No grupo de trabalhadores estudados foi verificada uma alta prevalência de hemoglobinopatias, sendo que aquelas de elevada incidência no continente africano foram as mais freqüentes ( $\mathrm{HbS}$, Tal.alfa e $\mathrm{HbC}$ ), bem como os portadores do traço falciforme apresentaram uma elevada interação com a talassemia alfa. Estes resultados reiteram a importância da continuação do estudo dessas hemoglobinas anormais na população brasileira.

A intensidade oxidativa da hemoglobina foi maior em trabalhadores portadores do traço falciforme, mesmo esta 
não sendo estatisticamente significativa, confirmando estudos anteriores e nos levando a crer que esses trabalhadores possam apresentar uma chance aumentada de sofrer uma meta-hemoglobinemia tóxica quando expostos ocupacionalmente a agentes meta-hemoglobinizantes.

\begin{abstract}
Hemoglobinopathies are frequent hereditary diseases in Brazilian population and have been a public health problem. This study reports the screening of abnormal hemoglobin among Fiocruz 's employees, as well as the impact of exposure to some factors such as, chemical substances, radiation, excessive cold or heat in sickle cell trait carriers. This impact has been analyzed by measuring methehemoglobin level and the presence of Heinz bodies. The samples were obtained from 2190 (4,7\%) individuals presented abnormal hemoglobin. Hemoglobin $S$ was found in $72,3 \%$ of individuals with abnormal hemoglobin constituting the most prevalent. The results distribution were: sickle cell trait in 3,2\% and associated with thalassemia in 0,2\%; thalassemia in 0,7\%; $A C$ hemoglobin in 0,4\%; thalassemia minor in 0,3\% and finally SS and $D$ hemoglobin in 0,05\%. Sickle cell trait carriers employees had a 14 times higher risk of increased methehemoglobin increase levels. Rev. bras. hematol. hemoter. 2005;27(3):183-187.
\end{abstract}

Key words: Hemoglobinopathies; occupational hazards; methehemoglobin; sickle cell trait.

\section{Agradecimentos}

Ao Dr. Paulo César Naoum por ter gentilmente cedido a técnica para a dosagem de meta-hemoglobina.

À Dra. Maria José de Andrada-Serpa pela correção do manuscrito e pelo indispensável apoio no dia a dia.

\section{Referências Bibliográficas}

1. Penna SDJ. Homo brasilis: Aspectos genéticos, lingüísticos, históricos e socioantropológicos da formação do povo brasileiro. ed. Ribeirão Preto, SP: Funpec-RP, 2002. 192.

2. Naoum PC, Domingos CRB. Doença falciforme no Brasil. Origem, genótipos, haplótipos e distribuição geográfica. J Bras Patol 1997; 33(3):145-153

3. Ramalho AS. O laboratório de hemoglobinopatias. In: As hemoglobinopatias hereditárias: um problema de saúde pública no Brasil. ed.da Revista Brasileira de Genética. Ribeirão Preto, SP 1986:129-147.

4. Jones SR, Binder RA, Donowho EM. Sudden death in sickle cell trait. Boston Med Surg J 1970;6:323-325.

5. Sears DA. The morbity of sickle cell trait a review of the literature. Amer J Med 1978;64:1.021-1.036.

6. Ramalho AS. Avaliação da morbidade do traço siclêmico em Campinas, SP. Ciência e Cultura 1979;31(supl.):607.

7. Ramalho AS. Talassemia minor, traço falciforme e deficiência de G6PD: dados de prevalência e de morbidade na região de Campinas, SP. Bol Soc Bras Hemat Hemoter 1985;7(134):133-136.

8. Fabron AJ. Morbidade do traço falciforme. Bol Soc Bras Hematol hemot 1986;8:93-95.
9. Souza PC. Avaliação dos produtos de degradação oxidativa da HbS em eritrócitos de doentes falcêmicos. Rev Bras Hematol Hemoter 2001;23(1):53-54.

10. Brasil. Ministério do Trabalho. Secretaria de Relações do Trabalho. Portaria n 24, dezembro de 1994. Diário Oficial 1994;1: 21.278-21.278.

11. Miranda CR. Doenças profissionais. Introdução à saúde e trabalho. Disponível em http://www.saudeetrabalho.com.br Acesso em 22 de out de 2002.

12. Naoum PC. Dosagem espectrométrica de metaemoglobina sem interferentes químicos ou enzimáticos. Rev bras hematol hemoter 2004;26(1):19-22.

13. Fleury MK. Determinação dos haplótipos do grupamento do gene da globina beta em pacientes com anemia falciforme no Rio de Janeiro.2000. 82f. Tese (Doutoramento em genética) - Universidade Federal do Rio de Janeiro, Rio de Janeiro. 2000.

14. Wenning MRSC et al. $\alpha$-Globin genes: thalassemic and structural alterations in a Brazilian population. Braz J Med Biol Res 2000; 33(9):1.041-1.045.

15. Lima JCS. Interação de anemia falciforme e alfa talassemia. Aspectos moleculares, clínicos, hematológicos e bioquímicos - Um estudo na população brasileira. 1997. Tese (Doutorado) - Universidade Federal do Rio de Janeiro, Rio de Janeiro, 1997.

16. Sheng K, Shariff M, Hebbel RP. Comparative oxidation of hemoglobins A and S. Blood 1998;91(9):3.467-3.470.

Avaliação: Editor e dois revisores externos.

Não há conflito de interesses

Recebido: 29/08/2005

Aceito após modificações: 05/09/2005 